\title{
Fly Reservoir Associated with Wohlfahrtiimonas Bacteremia in a Human
}

\author{
Jesse H. Bonwitt, Michael Tran, \\ Elizabeth A. Dykstra, Kaye Eckmann, \\ Melissa E. Bell, Michael Leadon, \\ Melissa Sixberry, William A. Glover
}

Wohlfahrtiimonas species bacteria were isolated from the bloodstream of a patient with septicemia and wound myiasis. Environmental investigations identified a Wohlfahrtiimonas sp. among insects in the Americas and in a previously undescribed vector, the green bottle fly (Lucilia sericata). The isolates possibly represent a new species within the genus Wohlfahrtiimonas.

$W$ ohlfahrtiimonas chitiniclastica is a rarely reported cause of bacterial infection that has been isolated in humans and other mammals from a variety of organs (online Technical Appendix Table, https://wwwnc.cdc. gov/EID/article/24/2/17-0913-Techapp1.pdf). In addition, Wohlfahrtiimonas spp. have been isolated from 4 species of nonbiting flies in Asia and Europe (1-4) that can cause myiasis, fly larvae infestation of a host's tissue. Wound myiasis has been reported in patients infected with $W$. chitiniclastica and with Ignatzschineria spp., an organism closely related to $W$. chitiniclastica (online Technical Appendix Table). These findings provide evidence that $W$. chitiniclastica is transmitted by flies or fly larvae during myiasis. However, no reported attempt has been made to isolate Wohlfahrtiimonas spp. or Ignatzschineria spp. from larvae associated with a patient. We report a case of Wohlfahrtiimonas infection in a man in Washington, USA, and results of environmental investigations.

\section{The Study}

The case-patient was a 57-year-old man who developed wet gangrene of the right ankle and myiasis below the

Author affiliations: Washington State Department of Health, Shoreline, Washington, USA (J.H. Bonwitt); University of Durham, Durham, United Kingdom (J.H. Bonwitt); Centers for Disease Control and Prevention, Atlanta, Georgia, USA (J.H. Bonwitt, M.E. Bell); Washington State Public Health Laboratories, Shoreline, Washington, USA (M. Tran, K. Eckmann, W.A. Glover); Washington State Department of Health, Olympia, Washington, USA (E.A. Dykstra); Yakima Health District, Yakima, Washington, USA (M. Leadon, M. Sixberry)

DOI: https://doi.org/10.3201/eid2402.170913 waist. Hematology at hospital admission was notable for leukocytosis and a predominance of neutrophils with a high ratio of band neutrophils (online Technical Appendix). Chronic cirrhosis, localized lung atelectasis, and multiorgan failure secondary to septic shock were diagnosed. The patient underwent amputation below the right knee but died 3 days after admission. Blood, urine, and tracheal aspirates collected $<8$ hours after admission revealed a mixed bacterial infection, including gram-positive cocci and gram-negative rods (online Technical Appendix). Propionibacterium acnes and Staphylococcus hominis ssp. hominis were isolated from blood cultures, in addition to an unidentifiable gram-negative rod. No medical history was available; proxy interviews excluded recent travel outside Washington.

We performed presumptive identification of the gramnegative rod with phenotypic studies and matrix-assisted laser desorption/ionization time-of-flight mass spectrometry (online Technical Appendix). Amplification and sequencing of the near full-length $16 \mathrm{~S}$ ribosomal RNA (rRNA) gene was performed, a phylogenetic tree was inferred by using the neighbor-joining method, and the topology was assessed by a bootstrap analysis of 1,000 replicates (online Technical Appendix). We used pulsed-field gel electrophoresis (PFGE) to assess isolate relatedness (online Technical Appendix).

Because larvae found on the patient had been discarded, we collected live and dead insects from the patient's home and identified them to genus or species level (online Technical Appendix). To remove surface contamination, all live fly larvae and adult specimens were rinsed 5 times with sterile phosphate-buffered saline (PBS), homogenized, and sequentially diluted. We cultured the first rinse, fifth rinse, and diluted homogenates to isolate Wohlfahrtiimonas spp. (online Technical Appendix).

We identified 6 species of flies (online Technical Appendix) and collected live larvae $(\approx 20)$ from the patient's house (Table, batch 1). We performed bacterial culture on a pooled sample of half of these larvae (Table, sample 2 ) and then individually on adult flies that emerged from the other half (Table, samples 3-5). One green bottle fly (Lucilia sericata) (Figure 1) was caught alive in the house in a sterile container and laid eggs inside the container before dying (Table, batch 2). We isolated a Wohlfahrtiimonas sp. from 2 of 6 insect samples on blood agar plates (Table, samples 2-7) but not from any other samples, 
Table. Culture results for Wohlfahrtiimonas spp. from samples collected from patient with septicemia and wound myiasis and the patient's home, Washington, USA*

\begin{tabular}{|c|c|c|c|c|}
\hline $\begin{array}{l}\text { Collection } \\
\text { batch no. }\end{array}$ & $\begin{array}{c}\text { Sample } \\
\text { no. }\end{array}$ & Specimen & Specimen description & Culture Wohlfahrtiimonas spp. \\
\hline NA & 1 & Blood & $\begin{array}{l}\text { Isolate sent to public health } \\
\text { laboratories from admitting hospital }\end{array}$ & $\begin{array}{l}\text { Aerobic growth on blood agar (isolate } \\
22912 \text { ) }\end{array}$ \\
\hline 1 & 2 & $\begin{array}{l}\text { Fly larvae (unidentified } \\
\text { species, } n \approx 20 \text { ) }\end{array}$ & $\begin{array}{l}\text { Larvae collected from underneath } \\
\text { carpet where patient was found }\end{array}$ & $\begin{array}{l}\text { Growth on diluted homogenate on } \\
\text { blood agar at } 25^{\circ} \mathrm{C} \text { (isolate } 22913 \text { ) }\end{array}$ \\
\hline 1 & 3 & $\begin{array}{l}\text { House fly (Musca } \\
\text { domestica) }\end{array}$ & Emerged from larvae of sample no. 2 & No growth \\
\hline 1 & 4 & $\begin{array}{l}\text { Unidentified species in the } \\
\text { family Calliphoridae }\end{array}$ & Emerged from larvae of sample no. 2 & No growth \\
\hline 1 & 5 & Calliphora vicina & Emerged from larvae of sample no. 2 & No growth \\
\hline 2 & 6 & $\begin{array}{l}\text { Green bottle fly and eggs } \\
\text { (Lucilia sericata) }\end{array}$ & $\begin{array}{c}\text { Green bottle fly caught inside the } \\
\text { patient's home and laid eggs inside a } \\
\text { sterile container }\end{array}$ & Not cultured \\
\hline 2 & 7 & Lucilia sericata larva & $\begin{array}{l}\text { Larva obtained from the egg in batch } \\
\text { no. } 2\end{array}$ & $\begin{array}{l}\text { Growth on fifth wash (isolate 22914) } \\
\text { and diluted homogenate (isolate } \\
22915 \text { ) on blood agar at } 25^{\circ} \mathrm{C}\end{array}$ \\
\hline NA & 8 & Meat and fruit & $\begin{array}{l}\text { Fed to flies from samples 3-7 were } \\
\text { extracted }\end{array}$ & No growth \\
\hline
\end{tabular}

including adult flies that emerged from the positive batch of larvae.

The isolates grew on blood agar, yielding colonies with a smooth center and rough edges, and displayed $\alpha$ hemolysis. Matrix-assisted laser desorption/ionization time-of-flight mass spectrometry yielded a presumptive result of W. chitiniclastica (online Technical Appendix). A phylogenetic analysis of the 16S rRNA gene sequence of all isolates (1,462 bp; see Figure 2 for GenBank accession numbers) showed that the most closely related type strains were $W$. chitiniclastica DSM $18708^{\mathrm{T}}(98.3 \%$ sequence similarity) and $W$. larvae JCM $18424^{\mathrm{T}}$ (97.3\% sequence similarity) (Figure 2). The PFGE pattern indicated that all isolates from flies and fly larvae were indistinguishable and $74 \%$ similar to that of the patient isolate (online Technical Appendix).

\section{Conclusions}

Our isolates possibly represent a new species in the genus Wohlfahrtiimonas based on the percentage sequence similarity with $W$. chitiniclastica and $W$. larvae type strains (5). We isolated Wohlfahrtiimonas sp. from insects in the Americas and in a previously undescribed host, the green bottle fly (L. sericata, Diptera: Calliphoridae). Previously, Wohlfahrtiimonas spp. have been identified in only 4 species of flies in Asia and Europe (Wohlfahrtia magnifica, Chrysomya megacephala, Hemetia illucens, Musca domestica) (1-4), each representing a different fly family (Diptera: Sarcophagidae, Calliphoridae, Stratiomyidae, and Muscidae, respectively). We isolated a Wohlfahrtiimonas sp. from a larva hatched from eggs laid by a fly in a sterile container, providing evidence that Wohlfahrtiimonas can be transmitted vertically.

$L$. sericata has been associated with $W$. chitiniclastica infection in a patient with myiasis and bacteremia only once, in the United Kingdom (6), but a definitive link could not be established in that case because larvae from the patient had been discarded. The scarcity of reports of Wohlfahrtiimonas spp. infections might be attributable to the difficulty in laboratory identification $(7,8)$ or because wound myiasis is routinely addressed with broad-spectrum antimicrobial drugs.

Because the pooled larvae (Table, sample 2) emerged as multiple fly species, we are unable to ascertain in which other species Wohlfahrtiimonas sp. growth occurred. Wohlfahrtiimonas was not isolated from these adult flies, which

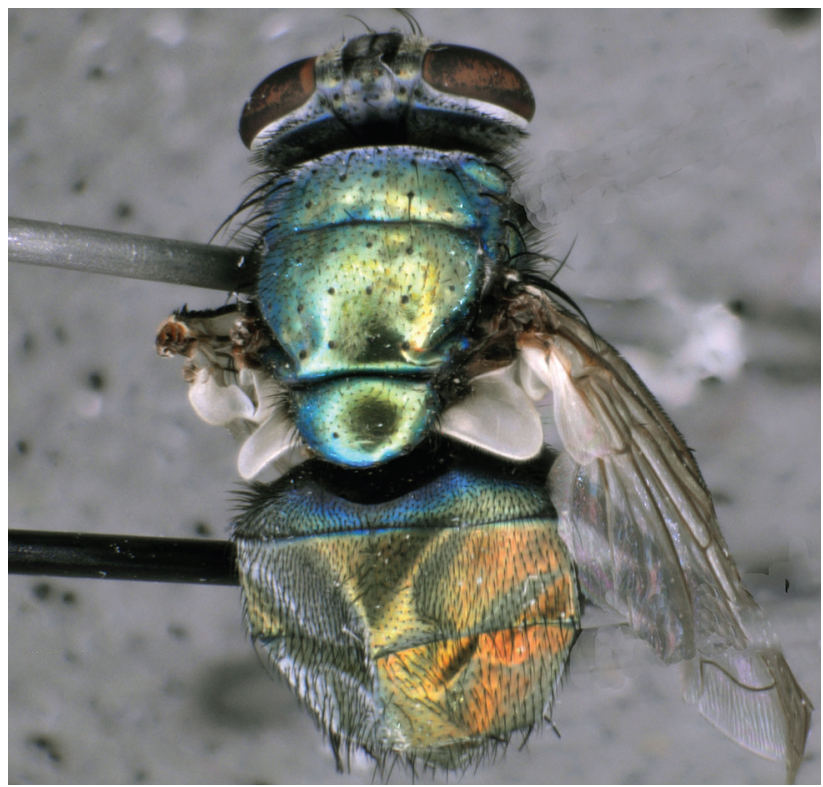

Figure 1. Green bottle fly (Lucilia sericata), caught inside home of patient with septicemia and wound myiasis in Washington, USA. The fly laid eggs inside a sterile container, and Wohlfahrtiimonas spp. were isolated from a larva hatched from these eggs. Photo courtesy of T. Whitworth. 
Figure 2. Neighbor-joining phylogenetic tree of $16 \mathrm{~S}$ rRNA gene sequences of Wohlfahrtiimonas spp. isolate from a patient with septicemia and wound myiasis in Washington, USA (laboratory identification no. 22912), isolates from flies and fly larvae (laboratory identification nos. 22913, 22914, 22915), and the most closely related type strains. Numbers at nodes denote bootstrap percentages based on 1,000 replicates; only values

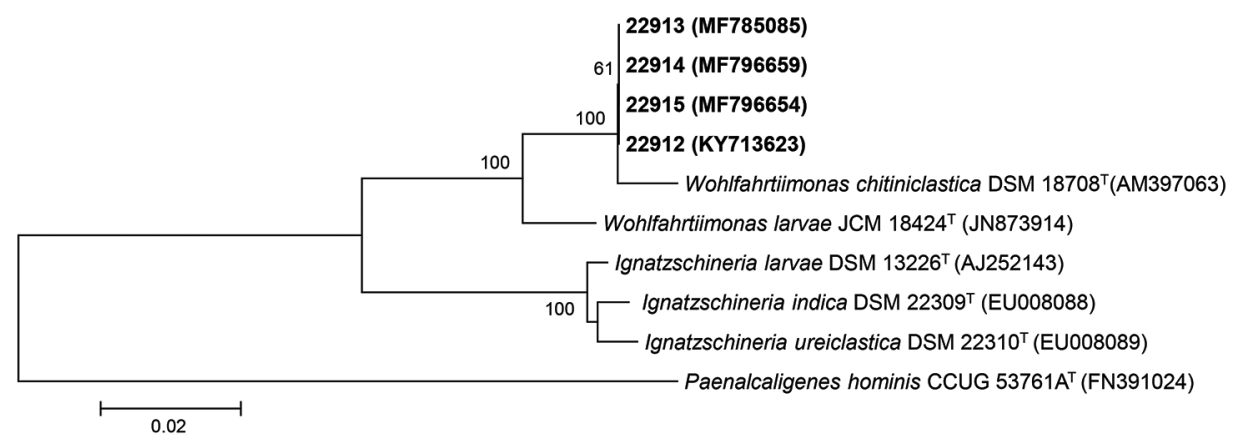
$>50 \%$ are shown. GenBank accession numbers are given in parentheses. Bold indicates strains isolated in this study. The tree was rooted with Paenalcaligenes hominis CCUG 53761 $\mathrm{A}^{\top}$ as the outgroup. Scale bar indicates substitutions per nucleotide position.

might be because the competent host was not present in the batch of larvae left to emerge or because of the association between Wohlfahrtiimonas spp. and flies during successive developmental stages. Indeed, previous studies isolated $W$. chitiniclastica from the gut of larvae and adult flies $(1,3,4)$, and Ignatzschineria spp. are hypothesized to play a role in larval development (9), indicating that these bacteria might belong to fly microbiota. In one study, the relative abundance of Ignatzschineria spp. fluctuated during life stages of $L$. sericata and was among the dominant bacterial genera during the larval and pupal life stages (10). Bacterial flora further decline during pupation, when reorganization of the intestinal tract leads to extrusion of the gut lining (11). These factors might explain why we did not isolate Wohlfahrtiimonas spp. from the adult flies that emerged, or alternatively, our protocol might have been of insufficient diagnostic sensitivity to detect Wohlfahrtiimonas spp. among adult flies.

The concurrent isolation of Wohlfahrtiimonas sp. from the blood of a patient with myiasis and from fly larvae found at the patient's home provides further evidence that fly larvae can act as vectors of Wohlfahrtiimonas spp. Because PFGE patterns of the isolates obtained from the fly larvae and from the patient's blood did not match, we cannot definitively identify the fly species that led to his infection.

We isolated Wohlfahrtiimonas sp. from a patient's blood along with other bacteria, precluding us from assessing the pathogenicity of our isolate. However, in 2 previous reports $(12,13), W$. chitiniclastica was the only bacterium isolated from the blood, indicating its pathogenic potential (online Technical Appendix Table 1).

Most cases of $W$. chitiniclastica infection have occurred among persons with a history of poor hygiene and exposed wounds (online Technical Appendix Table 1). Green bottle flies are among the most common species associated with myiasis in the United States (14), and risk for infection is expected during warm environmental conditions favorable to their development. In addition, green bottle fly larvae are the most commonly used larvae for maggot debridement therapy (15). Infection with Wohlfahrtiimonas spp. should be considered as a potential risk for patients undergoing this therapy.

\section{Acknowledgments}

We thank Marisa D'Angeli, Marcia Goldoft, and Travis Kushner for providing care to our maggots and flies; Denny Flodin-Hursh and Vance Kawakami for help with the field investigation; Terry Whitworth for assistance with fly identification and photography of L. sericata; Romesh Gautom, Tracie Gardner, and Marcia Goldoft for their advice and manuscript review; and Scott Lindquist for all of the above. We are grateful to the staff of the Washington State Public Health Laboratories and the Centers for Disease Control and Prevention (CDC) Special Bacteriology Reference Laboratory for their assistance with laboratory work.

This study was supported by the Washington State Department of Health Public Health Laboratories and CDC.

\section{About the Author}

Dr. Bonwitt is a veterinarian and Epidemic Intelligence Service officer assigned to the Washington State Department of Health. His research interests are zoonotic and emerging infectious diseases and qualitative research at the animalhuman interface.

\section{References}

1. Tóth EM, Schumann P, Borsodi AK, Kéki Z, Kovács AL, Márialigeti K. Wohlfahrtiimonas chitiniclastica gen. nov., sp. nov., a new gammaproteobacterium isolated from Wohlfahrtia magnifica (Diptera: Sarcophagidae). Int J Syst Evol Microbiol. 2008;58:97681. http://dx.doi.org/10.1099/ijs.0.65324-0

2. Cao XM, Chen T, Xu LZ, Yao LS, Qi J, Zhang XL, et al. Complete genome sequence of Wohlfahrtiimonas chitiniclastica strain SH04, isolated from Chrysomya megacephala collected from Pudong International Airport in China. Genome Announc. 2013;1:e0011913. http://dx.doi.org/10.1128/genomeA.00119-13

3. Gupta AK, Nayduch D, Verma P, Shah B, Ghate HV, Patole MS, et al. Phylogenetic characterization of bacteria in the gut of house flies (Musca domestica L.). FEMS Microbiol Ecol. 2012;79:58193. http://dx.doi.org/10.1111/j.1574-6941.2011.01248.x 
4. Lee JK, Lee YY, Park KH, Sim J, Choi Y, Lee SJ. Wohlfahrtiimonas larvae sp. nov., isolated from the larval gut of Hermetia illucens (Diptera: Stratiomyidae). Antonie van Leeuwenhoek. 2014;105:1521. http://dx.doi.org/10.1007/s10482-013-0048-5

5. Clinical and Laboratory Standards Institute. Interpretive criteria for identification of bacteria and fungi by DNA target sequencing, approved guideline (MM18-A). Wayne (PA): The Institute; 2008.

6. Campisi L, Mahobia N, Clayton JJ. Wohlfahrtiimonas chitiniclastica bacteremia associated with myiasis, United Kingdom. Emerg Infect Dis. 2015;21:1068-9. http://dx.doi.org/ 10.3201/eid2106.140007

7. de Dios A, Jacob S, Tayal A, Fisher MA, Dingle TC, Hamula CL. First report of Wohlfahrtiimonas chitiniclastica isolation from a patient with cellulitis in the United States. J Clin Microbiol. 2015;53:3942-4. http://dx.doi.org/10.1128/JCM.01534-15

8. Schröttner P, Rudolph WW, Damme U, Lotz C, Jacobs E, Gunzer F. Wohlfahrtiimonas chitiniclastica: current insights into an emerging human pathogen. Epidemiol Infect. 2017;145:1292-303. http://dx.doi.org/10.1017/S0950268816003411

9. Tóth EM, Hell E, Kovács G, Borsodi AK, Márialigeti K. Bacteria isolated from the different developmental stages and larval organs of the obligate parasitic fly, Wohlfahrtia magnifica (Diptera: Sarcophagidae). Microb Ecol. 2006;51:13-21. http://dx.doi.org/10.1007/s00248-005-0090-6

10. Singh B, Crippen TL, Zheng L, Fields AT, Yu Z, Ma Q, et al. A metagenomic assessment of the bacteria associated with Lucilia sericata and Lucilia cuprina (Diptera: Calliphoridae). Appl
Microbiol Biotechnol. 2015;99:869-83. http://dx.doi.org/10.1007/ s00253-014-6115-7

11. Greenberg B. Model for destruction of bacteria in the midgut of blow fly maggots. J Med Entomol. 1968;5:31-8. http://dx.doi.org/ 10.1093/jmedent/5.1.31

12. Rebaudet S, Genot S, Renvoise A, Fournier P-E, Stein A. Wohlfahrtiimonas chitiniclastica bacteremia in homeless woman. Emerg Infect Dis. 2009;15:985-7. http://dx.doi.org/10.3201/ eid1506.080232

13. Almuzara MN, Palombarani S, Tuduri A, Figueroa S, Gianecini A, Sabater L, et al. First case of fulminant sepsis due to Wohlfahrtiimonas chitiniclastica. J Clin Microbiol. 2011;49:23335. http://dx.doi.org/10.1128/JCM.00001-11

14. Sherman RA. Wound myiasis in urban and suburban United States. Arch Intern Med. 2000;160:2004-14. http://dx.doi.org/10.1001/ archinte.160.13.2004

15 Sherman RA. Mechanisms of maggot-induced wound healing: what do we know, and where do we go from here? Evid Based Complement Alternat Med. 2014;2014:592419. http://dx.doi.org/10.1155/2014/592419

Address for correspondence: Jesse H. Bonwitt, Centers for Disease Control and Prevention, 1600 Clifton Rd NE_Mailstop E92,

Atlanta, GA 30329-4027, USA; or Washington State Department of Health, 1610 NE 150th St, Shoreline, WA 98155, USA; email: jbonwitt@doh.wa.gov

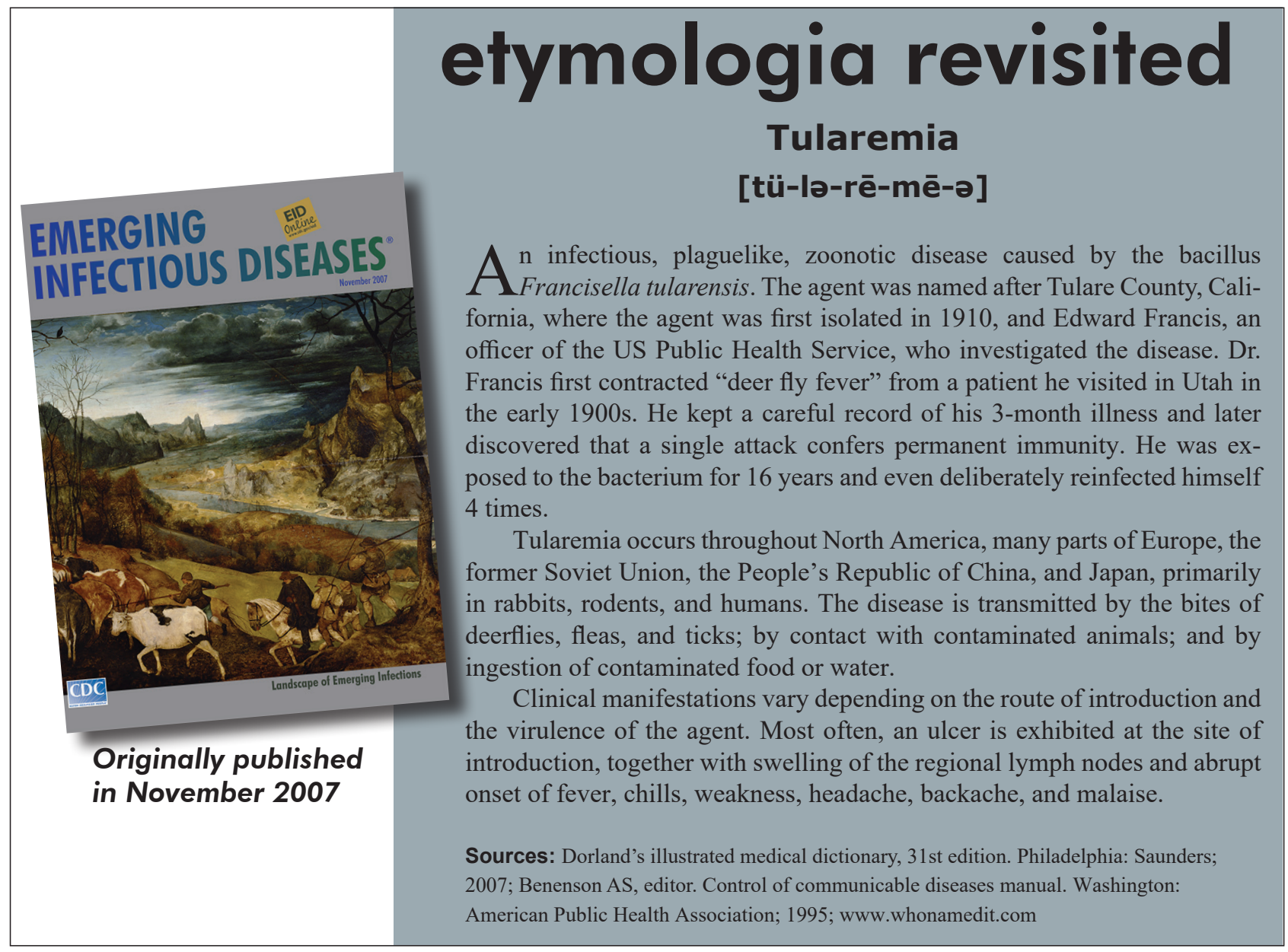

